\title{
Conception of a digital mobility platform for citizens in rural areas
}

\author{
Vera Spitzer \\ Institute for IS Research, University of Koblenz-Landau, \\ Germany \\ vesp91@uni-koblenz.de
}

\author{
Maria A. Wimmer \\ Institute for IS Research, University of Koblenz-Landau, \\ Germany \\ wimmer@uni-koblenz.de
}

\begin{abstract}
For many senior citizens living in rural areas, participation in daily activities, political affairs and cultural events is determined by the available mobility options to get to such activities. To support these citizens in their everyday life, an intelligent "Mobility-as-a-Service" (MaaS) application shall be conceptualized and implemented, which matches mobility offers of volunteer drivers, public transportation and taxi services with the mobility needs of the senior citizens. This paper introduces to the conception and design of a digital mobility platform for senior citizens in cooperation with an administrative district and six of its municipalities in Germany. Senior citizens are involved in the different phases of the development of a mobility solution through a co-creation approach and are significantly involved in the design and testing of the application. In this paper, we introduce the design phase of the development and present the results from five workshops that we conducted together with 57 seniors. During the workshops, the developed usage scenarios and mock-ups of the mobility application were evaluated by the participants. Based on the feedback and insights gathered from the users in the workshops, recommendations for the further implementation of the mobility app were given.
\end{abstract}

\section{CCS CONCEPTS}

-Applied computing $\rightarrow$ Computers in other domains; Computing in government; E-government.

\section{KEYWORDS}

Mobility application, scenario technique, mock-ups, citizens collaboration, co-creation, rural areas

\section{ACM Reference Format:}

Vera Spitzer and Maria A. Wimmer. 2021. Conception of a digital mobility platform for citizens in rural areas. In 14th International Conference on Theory and Practice of Electronic Governance (ICEGOV 2021), October 06-08, 2021, Athens, Greece. ACM, New York, NY, USA, 8 pages. https://doi.org/10.1145/ 3494193.3494249

Permission to make digital or hard copies of all or part of this work for personal or classroom use is granted without fee provided that copies are not made or distributed for profit or commercial advantage and that copies bear this notice and the full citation on the first page. Copyrights for components of this work owned by others than ACM must be honored. Abstracting with credit is permitted. To copy otherwise, or republish, to post on servers or to redistribute to lists, requires prior specific permission and/or a fee. Request permissions from permissions@acm.org.

ICEGOV 2021, October 06-08, 2021, Athens, Greece

(C) 2021 Association for Computing Machinery.

ACM ISBN 978-1-4503-9011-8/21/10 . \$ \$15.00

https://doi.org/10.1145/3494193.3494249

\section{INTRODUCTION}

The current era is characterized by the rapid development and everyday use of mobile devices, especially smartphones, which influence almost all aspects of human life [1.]. At the same time, the onset of demographic change is noticeable and poses many challenges in society, especially in ensuring independence and spatial mobility [2.]. In this context, the term mobility service describes the offer and implementation of a driving service through a mobile application called the SWiA app. Since many people have difficulties using private transport in old age, mobility is of particular importance in the context of demographic change [3.]. For many seniors living in rural communities, reaching the district administration to access administrative services can be difficult or even impossible [4.]. The same applies to everyday needs such as reaching grocery shops, sports clubs or meeting with family and friends. Public transport is sparsely provided in rural areas, combined with incompatible accessibility and limited timetables [5.], [6.]. Furthermore, private transport solutions such as taxis are often too expensive for regular use. ${ }^{1}$ Participation in daily activities is an important factor for a self-determined and independent life in rural areas [7.]. With these challenges in mind, the German administrative district CochemZell and six of its municipalities have initiated the development of an intelligent "Mobility-as-a-Service" (MaaS) application for senior citizens in collaboration with the University in Koblenz in the project SWiA (Smartes Wohnen im Alltag) ${ }^{2}$. Part of the project is the conception and prototypical implementation of a digital mobility application as a MaaS [10.] (for details on MaaS see also [8.], [9.]). The application for mobile devices (the SWiA app) shall intelligently match the mobility needs of senior citizens with all available mobility offers. For this, the requirements of both, seniors in need of mobility offers, and mobility providers (e.g. volunteer drivers, public transportation, taxi drivers, community buses, etc.) were collected and a prototype mobility solution was developed. Ultimately, by bundling and combining all available mobility services in a user-friendly mobile application, the SWiA project shall make a significant contribution that senior citizens continue to live in their familiar surroundings. At the same time, users can actively participate in the project and contribute to the digital transformation of a relevant area of society. In order to meet the users' needs, we applied a co-creation approach by constantly refining the design and prototype implementation of the SWiA app together with the test users along workshops.

\footnotetext{
${ }^{1}$ Project outline on the implementation of model and demonstration projects $(\mathrm{MuD}$ projects) „Land.Digital - Chancen der

Digitalisierung für ländliche Räume“, Federal Programme for Rural Development, 2018. https://www.ble.de/DE/Projektfoerderung/Foerderungen-Auftraege/ Kompetenzzentrum-Laendliche-Entwicklung/LandDigital/LandDigital_node.html (Last accessed on 10th September 2021)

${ }^{2}$ https://swia-cochem-zell.de/ (last accessed on 10th September 2021)
} 
This paper outlines the concept of the digital mobility platform and presents part of the development of the mobility application and the co-creative approach. The primary goal is to investigate the benefits of involving citizens in the development process of an app and thus to derive user requirements at an early stage and implement them in the application. The structure of the paper is as follows: Section 2 introduces the theoretical background of developing mobility applications. Section 3 gives an overview of ridesharing solutions in the literature. Section 4 outlines the methodological approach of co-creation and the use of scenario technique as well as mockups in designing and prototypically implementing the SWiA app. Section 5 presents the results of five workshops and the evaluation of user feedback. Finally, section 6 summarizes the results of the work and provides an outlook on the next steps of the project.

\section{MOBILITY APPLICATIONS}

The development of mobile applications or applications for smart devices (e.g. smartphones) is a constantly evolving filed of particular interest in business and science [11.]. A mobile application is a type of software developed for mobile devices (e.g. smartphones or tablets) that performs certain tasks for the user. Tablets and smartphones differ mainly in their form factor, screen size and the ability to make calls. In addition, mobile applications are made available via app stores for different platforms or operating systems [12.]. The equipment of mobile devices with a variety of sensors, tools and technologies (e.g. camera, GPS, Bluetooth, e-mail, WLAN) enables a multitude of implementation options for mobile applications. Functions of these applications are e.g. browser use, chatting, multimedia functions, navigation, etc. Due to ubiquitous networking, mobile applications are used to bridge spatial distances, at any time and in different places [1., 12., 13.]

The mobility of these applications therefore lies in the portability, the location-independence of use and the binding to portable devices. In the context of this work, the focus is on spatial mobility. This results from the need, but also from the necessity, to carry out spatially separated activities such as living, working, educating oneself, shopping. Mobility is understood as a physical, temporary change of location in order to carry out an activity [3.]. To achieve digital support in mobile government, the concept of "Mobility-as-a-Service" needs to be considered [8., 9., 14.]. The idea behind MaaS consists of three main elements to ensure integrated and seamless mobility. First, MaaS should offer the possibility to book a ticket across all modes of transport through one account. Second, it should offer the possibility to book certain combinations of mobility services as a package in advance. Third, MaaS should provide all travel information of all transport modes through one application or digital user interface [15.]. Seamless mobility chains and the emerging demographic change have evolved in science and politics to foster mobility in old age. From 2010 to 2015, the Federal Ministry of Education and Research in Germany funded projects under the topic of "Seamless mobility until old age". ${ }^{3}$ According to [16.], the creation of a transport platform for older people is necessary that shows alternative mobility options and provides all the necessary information to assess the suitability of the option.

\footnotetext{
${ }^{3}$ https://www.bmbf.de/foerderungen/bekanntmachung-586.html (last accessed: $10^{\text {th }}$ September 2021)
}

Furthermore, in the topic of "mobility in old age", accessibility is important and must be supported by the transport platform [17.].

The development of the mobile application SWiA first required a literature and market research so that the essential findings and solutions in the field of mobility are considered. Thus, positive features of these solutions should be integrated into the SWiA app from the beginning and evaluated together with the users. Therefore, the next chapter investigates existing ridesharing solutions.

\section{RIDE SHARING SOLUTIONS}

In the mobile application developed as part of the SWiA project, senior citizens should be able to offer rides and book the rides offered by other users. In order to decide on the most viable approach to implementing this, existing approaches of ride-sharing solutions from scientific literature and practical solutions were investigated. Tian et al. developed "Noah", a dynamic, large-scale, real-time ridesharing system that matches users' ride requests with taxis. Taxis can match multiple users at the same time as long as pre-determined time constraints are met. The real-time algorithm that serves as the basis for the system is based on three main components: the shortest path algorithm module can calculate the distance between users and taxis. This algorithm is then used by the dynamic matching module to find the set of taxis that can pick up users as quickly as possible and provide the user with a choice of taxis. To ensure that the system always has an overview of all taxis and their journeys, the mobile indexing module keeps in touch with all taxis that regularly update their location [18.]. Ma et al. describe T-Share, a taxi ride system developed to explore dynamic carpooling. Users can submit ride requests via a mobile application, specifying the time and the starting location and destination. An operating center then matches the ride request with existing taxi rides and assigns a taxi to the user. Once the trip is booked by the user, a scheduling algorithm inserts the trip into the selected taxi's schedule [19.]. Through the SHAREK solution, users can search for rides and select a maximum price and waiting time in addition to the starting point and destination. Suitable drivers are then selected from a pool of available drivers based on the lowest price and waiting time. By focusing on these two variables, the shortest route does not need to be calculated for driver selection [20.]. Qadir et al. propose a recommendation framework for ride sharing services called HASVR. It assigns an aggregate score to vehicles offering ride-sharing services to users and selects the optimal match based on this score. The score is based on a variety of parameters, including the capacity of the vehicle, the fare and the time taken to reach the user [21.].

The various ridesharing approaches presented in this section all focus on sharing rides with private taxi companies in large cities. For these approaches to work, there must be enough taxi drivers willing to pick up passengers at any time. This does not correspond to the use case needed for the project SWiA, as the drivers are all elderly people who only want to offer ridesharing services if they are going to the respective destination anyway. Unfortunately, no scientific literature on matching private occasional carpooling could be found during the literature search. Other examples of classic ridesharing have become known primarily through the commercial offers of Uber and BlaBlaCar. In both concepts, private individuals can offer commercial rides via a mobile application and are thus 
networked with ride seekers [22.]. A notable project with a similar scope to SWiA is the online management service "Hüttis Mobilitätsportal" (Hüttis Mobility Portal) of the Hüttener Berge association municipality in Schleswig-Holstein, Germany. ${ }^{4}$ It is only available as a website and not as a mobile application, although the website can be viewed in a browser on mobile devices. The mobility portal allows citizens to search for a variety of transport options, including public transport, community buses, carpooling and hitchhiking. Users cannot search for connections with multiple transport options at the same time, but the developers have expressed interest in adding such a feature in the future. For some means of transport, such as the citizens' bus, users can book a ride via the mobility portal.

The simplest solution for implementing a basic ride-sharing service in the mobile application is for users to offer ride requests in the mobile application, specifying their starting point and destination. More sophisticated approaches that include features such as stopovers or dynamic changes to the route could be implemented in the future as part of the project. In this context, the software should be a user-friendly system that allows users to book transport options with mobility providers. To make booking rides as easy as possible, payment should be made through an e-payment system and users should be able to set a monthly budget for their expenses. Mobility providers should be brought together by the project. By combining different mobility services, e.g. a public transport connection with a taxi, the capacities of the different mobility providers can be better utilized. By enabling "sharing economy" mobility options, the overall costs of transport for the different users are reduced. ${ }^{5}$

\section{METHODOLOGY}

\subsection{Scenario Based Design and Mockups}

Scenario-based design is a collection of methods used for strategic planning and decision-making in projects with visions of the future. It is used to gather information from the perspective of stakeholders in addition to background documents. The methods are used at an early stage of the development process to guide the development of a future system. Unlike formal approaches that model specific tasks, scenario-based design focuses on describing how users interact with a system to perform tasks or other activities. Scenario-based design has been a popular approach for over 50 years and is still widely used [23.-27.]. Scenarios are textual descriptions of a topic to be addressed. They consist of structured or unstructured stories in the language of the users. The stories take place in a hypothetical, possible future, predefined environment and involve one or more users performing a specific task. The users or actors in the scenarios are usually functional. In some cases, they may be based on real people or even represent real people [24.-29.] Ratcliffe divides the construction of scenarios into two basic types:

\footnotetext{
${ }^{4}$ Willkommen bei Hüttis Mobilitätsportal | Amt Hüttener Berge: https://www.amt huettenerberge.de/buergerservice/mobilitaetsportal/ (Last accessed on 09.05.2021)

${ }^{5}$ Project outline on the implementation of model and demonstration projects $(\mathrm{MuD}$ projects) „Land.Digital - Chancen der

Digitalisierung für ländliche Räume“, Federal Programme for Rural Development, 2018. https://www.ble.de/DE/Projektfoerderung/Foerderungen-Auftraege/ Kompetenzzentrum-Laendliche-Entwicklung/LandDigital/LandDigital_node.html (Last accessed on 10th September 2021)
}

Backward scenarios involve the selection of several future situations. In scenarios, an attempt is made to find paths that lead to the selected future situations. In future-forward scenarios, several future situations are projected based on an analysis of current forces and their possible developments [23.]. Fahey and Randall classify scenarios into four categories: Global scenarios guide managers to different future environments that have different implications for long-term investment or management decisions; Industry scenarios allow managers to identify possible future states of an industry and the differences between these states - this helps them to examine the further evolution of these future states and the decisions that would need to be made by an organization to take the lead in each of these states; Competitor scenarios allow managers to identify and test the strategies of competitors in different circumstances; finally, Technology scenarios assist managers in making decisions on technological issues. It helps them understand the opportunities, risks and choices that are part of a possible future [30.].

The SWiA project team developed several basic scenarios to showcase the design and functionality of the application during the workshops (e.g. driving home from hospital, driving to a hiking trip, driving to the hairdresser, etc.). With the help of these scenarios, citizens were able to understand the initial situation and understand each step of booking a ride using the SWiA application. The SWiA scenarios could be classified as future usage scenario. An example is outlined below:

Mrs. Schmidt and her husband are two senior citizens living in a village of the rural municipality Dohr. In the scenario, Mrs. and Mr. Schmidt (considered as one actor searching for a mobility service) are at a hospital and want to be driven home. They are familiar with their smartphone and they have heard about the SWiA app, where they can search for a suitable mobility service to get to their home. In the first of four steps, Mrs. and Mr. Schmidt install the mobile application on their smartphone, register and save their payment information. In the second step, they search for the next available ride options that can take them from the hospital to their home in Dohr. In the third step, they select a voluntary driver, who offers a suitable transportation service on a voluntary basis. In the last step, the passengers rate the ride after reaching their home.

The mobile application supports and interacts with the couple by guiding them through the process and displaying all relevant information. The voluntary driver who offers the ride is the second actor in this scenario. All the interactions with senior citizens are happening through the mobile application that also the mobility service provider uses.

Based on this textual scenario description, an animated storytelling poster as shown in Figure 1 was developed. The aim of the poster was to generally explain the usage scenario to the seniors to give an overview and context in the focus group workshops. The poster is divided into two sections: The top half describes the environment in which the scenario takes place. The lower half is divided into 4 lines. The first line shows the steps that are carried out in the scenario with illustrations. The second line describes the 


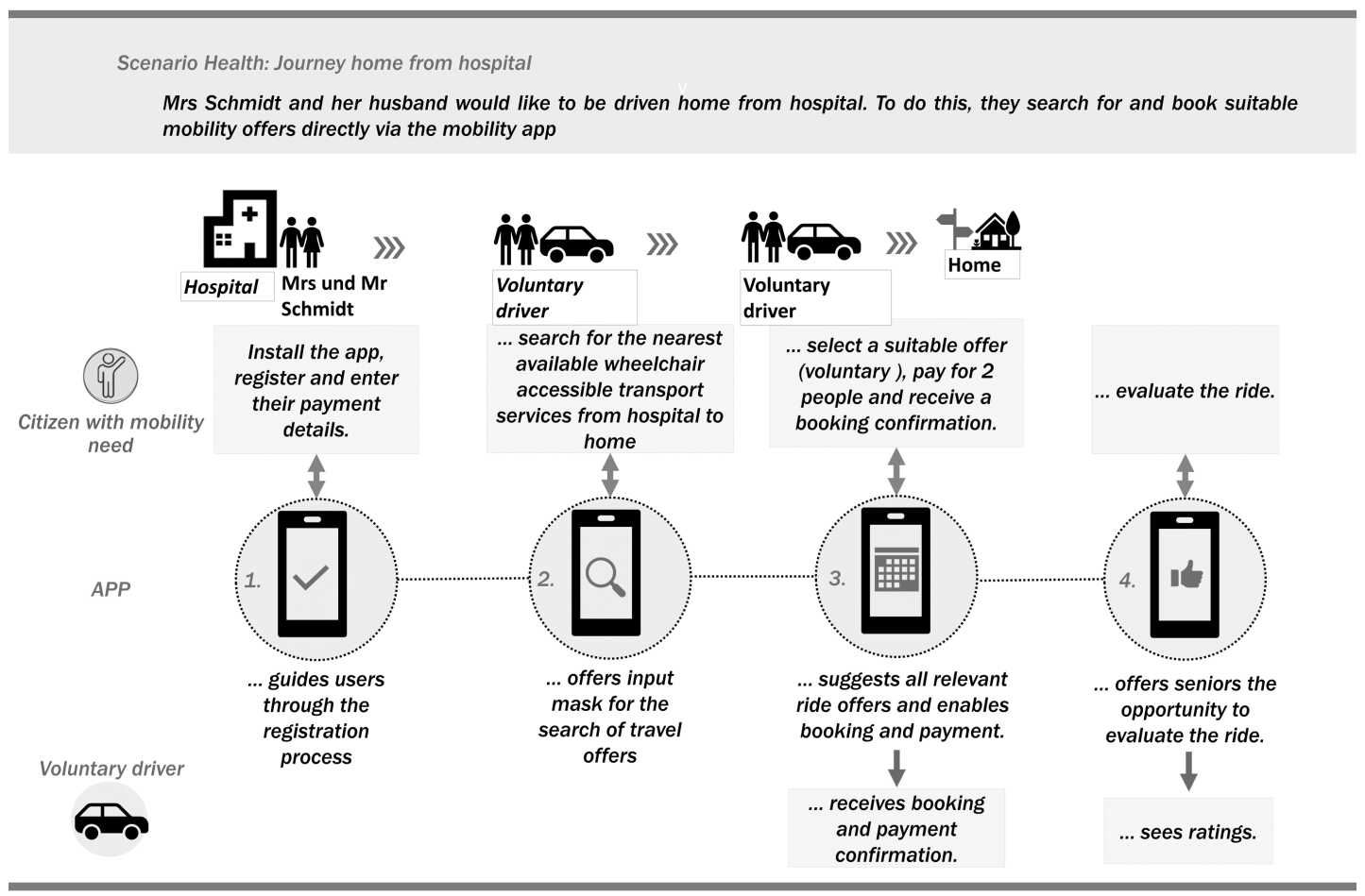

Figure 1: Usage Scenario - Journey from hospital to the home

actions that the seniors with mobility needs perform in each of the four steps. The third line describes the functions of the mobility application and the interaction of the application with the actors. The last line describes the actions of the private taxi companies.

As part of the workshop development for the SWiA project, a first set of mock-ups were created and presented in Figma ${ }^{6}$. Mockups are graphical representations commonly used to generate and communicate ideas. They can be fully or partially functional and navigable models or simple sketches of an application. In software development, they usually represent the user interface of an application under development. When interacting with potential users of an application, mock-ups are also used to capture and validate requirements [31.], [32.]. Especially when considering mobile application development, mobile interface design plays an important role. The user interface (UI) is the main factor of the user experience and must be created considering the limited screen size, different device categories such as tablets and smartphones, and device capabilities. Users should be able to use the UI intuitively and without much training [33., 34.].

Based on this first set of mock-ups, further mock-ups were developed, building on the scenario for the group workshops. The specialized tools provide functions to run the mock-ups as prototypes on computers and mobile devices. Although Figma offers the possibility to run the created mock-ups as prototypes on a device,

\footnotetext{
${ }^{6}$ Figma interface design tool: https://www.figma.com/ (Last accessed on 09.05.2021)
}

this functionality was not used in the focus group workshops. Instead, the created mock-ups were exported as graphical files and shown to the participants in the intended order [35.]. Kascak et al. recommend conducting user tests of the UI throughout the design process. These tests should involve participants from the end-user population. Presenting the mock-up during workshops will continuously engage seniors, who are the most important end-user population [34.]. Table 1 shows a series of mock-ups exploring part of the original user interface of the SWiA application. Overall, for each of the interactions with the mobile app described in the scenario, a corresponding mockup was developed and discussed together with the users. In this way, users could communicate possible difficulties with the user interface or in the app's processes from the beginning.

\subsection{Development Approach and workshops}

The project is conducted from July 2019 to March 2022 in four phases (see Figure 2) which are described below. In all phases, user input was taken into account using a co-creation approach. In the first phase, the specific needs, requirements and demands of seniors and mobility providers were collected and evaluated [10.]. This was done through interviews and surveys with the different stakeholders. By surveying user needs in face-to-face interviews, we were able to identify a wide range of requirements for the app. At the same time, suitable technical solutions were researched that can fulfil the expected requirements. In the second phase, which 
Table 1: - Examples of the mockups used
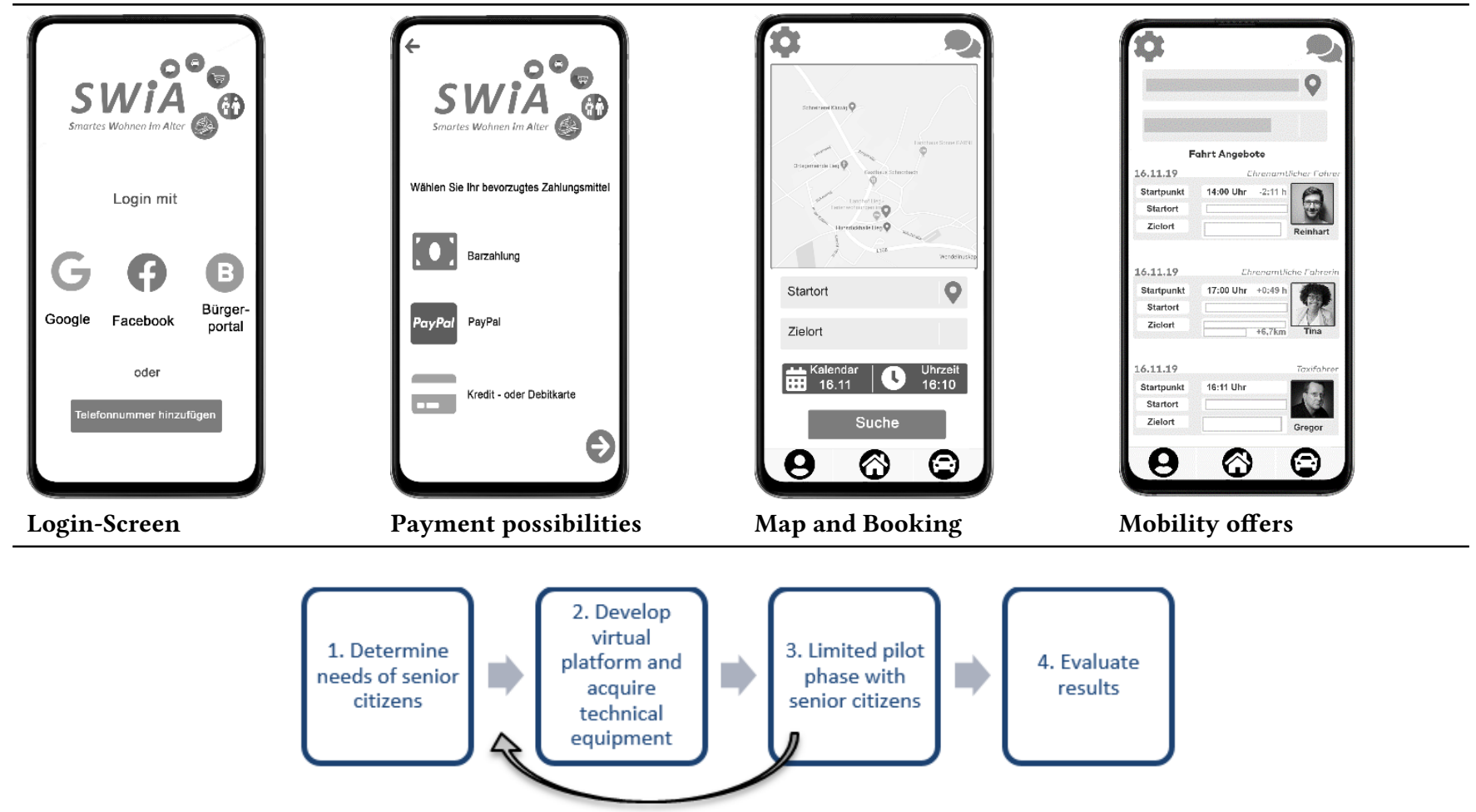

Figure 2: - Phases of application development

partially overlaps with the first phase, the requirements for the virtual platform were collected through moderated networking workshops. Furthermore, the software development was carried out to deliver a prototype of the SWiA app. In the third phase, the developed mobile application of SWiA was used by senior volunteers in a piloting phase. The last phase aims to evaluate the results of the co-creative development of the SWiA app with senior citizens.

The citizens received the necessary technical equipment and were trained in the independent use of the SWiA application in various workshops and information events. Participation in this pilot phase is free of charge for the volunteers. In the final phase, the experiences of all stakeholders will be collected and documented. Important success factors as well as barriers in the project will be identified and shared with third parties.

In this paper, we focus on the second phase of the app development. In this phase, we started with the development of mobility scenarios and mockups so that initial findings related to processes, user interface and functionalities can be evaluated with users. Phase 2 takes place in several iterations, as in addition to the mockups, the technical prototype is also discussed with users in further workshops and before the piloting phase 3 . The focus group workshops were conducted between January and July 2020 and lasted two hours each. Participants were invited personally and by email by the respective municipality. In addition, a call for participation was published in the local newspaper and gazette to ensure that as many users as possible attended the workshops. The first workshop in January could still be held physically, while the other workshops from mid-May onwards could only be held via digital conferences due to the Corona pandemic. While more than 20 people participated in the first workshop, the digital hurdle had to be overcome first among the senior citizens. For this purpose, the participants were trained in the use of Zoom conferences.

The workshops were guided by the following questions:

1. Does the scenario correspond to a real process? What adjustments are necessary?

2. Do the individual user interfaces contain all the necessary information?

3. Are the representations of the user interfaces clear, easy to understand and well chosen?

4. Does the app include all the functions that users expected?

5. Are the structure of the app and the user guidance logical and understandable?

In total, the scenarios and mock-ups were discussed in five workshops with 57 participants from 5 different municipalities to gather input from seniors in the development approach. At the beginning, the project scope was presented, together with the project partners and the schedule for the upcoming workshops. After that, the preliminary research findings from the interviews and the interaction so far in the workshops were presented. Then the main part of 
the workshop - the scenario interaction and mockup discussion was conducted. The scenario interaction was conducted along a pre-formulated choreography detailing each step of the interaction. All user comments were documented along the mockups in the workshops. In this way, adjustments could be implemented directly in the application and the improvements or further developments evaluated in the next workshop session.

\section{RESULTS OF WORKSHOPS}

The results and comments of the users from the workshops are described below. The results are described along the following criteria: General requirements for the app, payment options, search for mobility providers, booking for rideshare offers and rating function.

General requirements for the app

The font size of the app should automatically adapt to the size of the individual device screen, without manual changes. Older smartphones in particular are still smaller and the app content can be difficult to read if the web design is not responsive. Therefore, carry out tests to see if this adjusts automatically depending on the software version (for some older devices there are no new updates). Furthermore, mobility providers should have the possibility to rate users after a successful journey. This requirement is desirable for voluntary rides, as drivers want to get a first impression of passengers before the ride. The mobile application could allow users and mobility providers to exchange messages about non-transport matters. Seniors noted that the application should start directly with the option "Search rides" on the home screen so that booking rides is as easy to find as possible. When calculating the fare for train journeys, benefits such as a BahnCard (in Germany) should be displayed directly in the fare calculation. Users should be informed about delays of booked or bookmarked public transport connections. This could be done through a push notification. In addition to the regular login options of email, Facebook and Google, the application should also enable a link to the user account of the administrative portal of the district. In addition, WhatsApp should enable another login function. The accessibility needs of individual users should be indicated when booking journeys and thus also be visible to mobility providers.

Payment options

Users noted that debit cards and credit cards should not be listed as one option, but should be selectable individually. In addition, participants noted that they should not add a mandatory payment method when setting up a user account, as long as cash payment is always an option in the app. When entering credit card details in the app, the CVC (Card Validation Code) should not be saved, but should be asked for again with each application. This is the only way seniors can trust that such sensitive data is handled securely in the app.

\section{Search for mobility providers}

The search function for possible locations should be equipped with a scroll function. For example, if the term hospital is entered, all hospitals in the area should also be displayed in the application. This way, the user can select a destination by scrolling without having to enter further information manually. The address automatically determined by GPS should be as accurate as possible when searching for ride offers. Users want to be able to save favorite seats and always have the home address displayed first. The available seats must be displayed with the individual ride offers. It is misleading if, for example, two people book a journey in a family van, but only one seat is available due to the family occupants. This applies to all travel offers. When searching for trips, a function should be set up that allows the entry of "number of persons". In the list of results, only those travel offers should then be displayed that can provide the desired number of seats. The same applies to the offers of taxi drivers. In this way, vehicles can be optimally utilized and empty journeys avoided. As a further feature, it should be possible for mobility providers to store individual stopovers in the route. This function also allows users along the route to book a ride.

\section{Booking for ride offers}

The seniors were unsure what personal data would be transferred to the mobility provider in case of a successful booking. The users would like to see an overview of what data is ultimately transmitted to the drivers. Participants would also ride with a person they do not know personally. A photo of the driver would be helpful to get a first impression. Another comment from a participant was that the age of the driver and the vehicle type should be displayed in the app. The question of data protection arises when specifying the vehicle registration number. It would be helpful to indicate the color of the vehicle or a photo of the vehicle so that the passenger recognizes the driver when picking him up. It was also noted that the nationality of the driver could be indicated so that the passenger knows which language the driver speaks. As the public transport providers were not yet able to provide interfaces for the implementation of booking options at the time of the workshops, the only option available in the scenarios is to book a journey in advance. The option to book a public transport journey in advance is understandable for most participants, but should also be clearly displayed in the app. The app would be more likely to be used if it was also possible to make a booking in the future. It is desired that the booked trip is entered directly in the calendar app. It is desired that the user is informed about the delay, e.g. as a push message. When the journey is booked, the entry screen should reappear.

\section{Rating}

Ratings should only be visible by clicking on the respective profile. Basically, ratings are seen critically in the case of volunteer drivers, since in the case of commercial service providers the company is rated and less the person carrying out the service. Besides, nobody wants to be on the last place of the ranking. The textual rating should be limited to a certain number of characters so that the rating does not become too extensive. Many aspects are only a query of subjective perceptions. Furthermore, there was the question of the reliability of a rating (example hotel ratings and reality). The rating function should be kept simple, otherwise the procedure is too confusing for seniors. A general rating with stars and the awarding of a "thank you" is sufficient. The points system is seen critically for volunteer providers, as the driver offers the ride on a voluntary basis. The driver should be able to indicate whether or not he/she wants to contribute to the cost of the ride. Gamification elements such as collecting ride points in a leaderboard are more relevant for the younger generation according to the participants. 
The rider should also be able to choose whether or not to collect points. It should also be possible to indicate on the passenger's profile how they would like to contribute to the voluntary ride. For example: giving a tip, contributing to the fuel costs or inviting for coffee.

The results of the workshops aimed to discuss the individual functions and elements of the mobility application together with the senior citizen. The aim of the co-creation approach is to proceed as small-step as possible so that the individual functionalities of the technology are evaluated. In particular, elderly with low affinity for technology need an easy-to-use user interface for booking mobility services. As developers of the application, it is often difficult to identify the actual hurdles in using the functionalities, so the exchange with users reveals difficulties in handling at an early stage. The joint evaluation and discussion of the developed mockups showed where the development team needs to take a more critical approach:

As noted in the overview of ride-sharing, the approach to matching ride-sharing offers with ride-sharing requests is a very simple one: senior citizens offering ride-sharing submit a starting point and an ending point. Subsequently, when other senior citizens search for rides that match both the starting and ending points, the ride-sharing offer is included in the search results. As seen in the collected findings that are presented, a more sophisticated approach to ride-sharing should be pursued. This could include the option to add stopovers when offering rides, the automatic suggestion of stopovers, navigation functions and adding stopovers during a ride.

Furthermore, sensitive user data must be stored securely in the application, but at the same time it must be clear to the user what data is passed on to the mobility provider when a journey is booked. Sensitive information such as car registration numbers or mobile phone numbers should not be stored in the profiles, but identifying features such as the user's profile picture or the brand/color of the vehicle should be visible when booking. At this point, the current provisions of the GDPR must be taken into account and implemented. In addition, users want an easy-to-use user interface. This means that the creativity of an app's various functions must be used sparingly, as seniors in particular lose track of the app. Another controversy arose during the evaluation in connection with the rating system. On the one hand, half of the users wanted voluntary rides to be rated so that less suitable drivers could be filtered out by such classifications. On the other hand, concerns arose that ratings could be deliberately manipulated. Here, seniors feared that fewer voluntary rides would be offered because they feared a bad rating.

Overall, it was possible to discuss the individual points in detail and derive solutions for the SWiA app that were accepted by the elderly users.

\section{CONCLUSION}

After the first phase of the co-creation approach for the development of a mobility app, in which the needs of the users were collected through interviews, this paper dealt with the conception of the mobility app. For this purpose, a literature research on mobility solutions and car sharing solutions was conducted. In addition, various usage scenarios were developed with the help of the scenario technique. Mock-ups were developed for an initial technical evaluation so that the individual interaction could be discussed in detail within the workshops. Especially in the online sessions, the scenario technique and mock-ups enabled interactive user participation so that the users could actively shape the app to be developed.

A total of 57 senior citizens participated in five different workshops, so that we were able to record different perspectives of the participants. Not all wishes could be considered so far in the development of the prototype. In particular, the booking options for taxi rides is a feature to be implemented in the near future.

Due to the Corona pandemic, the planned number of users could not be fully reached. However, research and development team could quickly convert to digital channels to continue the development of the SWiA app with a co-creative approach. The drawback of this approach was that not all seniors could participate in the workshops due to their lack of meeting technical requirements. For the piloting of the SWiA application, the municipal partners therefore set up working groups in each municipality to regularly test the functionalities so that steady progress can be made in the further phases 3 and 4 along the project plan. Since these latter phases are currently ongoing, we will report on the implementation of the third phase and the evaluation of the SWiA app in future publications.

\section{ACKNOWLEDGMENTS}

This research was supported by the Federal Office for Agriculture and Food, Germany, Ref. 2818LD026. For further info see swiacochem-zell.de.

\section{REFERENCES}

[1.] Sarwar, M., Soomro, T.R.: Impact of Smartphone's on Society. Eur. J. Sci. Res. 98, 216-226 (2013)

[2.] Frevel, B.: Herausforderung demografischer Wandel. VS Verlag für Sozialwissenschaften, Wiesbaden (2004).

[3.] Steinrück, B., Küpper, P.: Mobilität in ländlichen Räumen unter besonderer Berücksichtigung bedarfsgesteuerter Bedienformen des ÖPNV, Braunschweig (2010).

[4.] Haefker, M., Tielking, K.: Alter, Gesundheit, Partizipation: Alternative Wohnund Versorgungsformen im Zeichen des demografischen Wandels. Springer VS, Wiesbaden (2017).

[5.] Buehler, R., Pucher, J.: Demand for Public Transport in Germany and the USA: An Analysis of Rider Characteristics. Transp. Rev. 32, 541-567 (2012)

[6.] Porru, S., Misso, F.E., Pani, F.E., Repetto, C.: Smart mobility and public transport: Opportunities and challenges in rural and urban areas. J. traffic Transp. Eng. (English Ed. 7, 88-97 (2020).

[7.] Soder, M., Peer, S.: The potential role of employers in promoting sustainable mobility in rural areas: Evidence from Eastern Austria. Int. J. Sustain. Transp. 12, 541-551 (2018).

[8.] Apaoja, A., Eckhardt, J., Nykänen, L.: Business models for MaaS. In: ICoMaaS 2017 Proceedings, Tampere, 8-20 (2017).

[9.] Finger, M., Bert, N., Kupfer, D.: Mobility-as-a-Services: from the Helsinki experience to a European model? Eur. Transp. Regul. Obs. (2015)

[10.] Spitzer, V., Wimmer, M.A.: User Needs for a Mobility App to Support Living in Rural Areas. In: Edelmann, N. et al. (Hrsg.) Electronic Participation. Proceedings of ePart2021, 77-89. Springer, Cham (2021). https://doi.org/10.1007/978-3-03082824-0_7.

[11.] Xanthopoulos, S., Xinogalos, S.: A comparative analysis of cross-platform development approaches for mobile applications. In: Proceedings of the 6th Balkan Conference in Informatics on - BCI '13. S. 213-220, New York (2013).

[12.] Islam, R., Islam, R., Mazumder, T.A.: Mobile application and its global impact. Int. J. Eng. Technol. 10, 104-111 (2010).

[13.] Islam, N., Want, R.: Smartphones: Past, Present, and Future. IEEE Pervasive Comput. 13, 89-92 (2014)

[14.] Smith, G., Hensher, D.: Towards a Framework for Mobility-as-a-Service Policies. Transp. policy. 89, 54-65 (2020). 
[15.] Kamargianni, M., Li, W., Matyas, M., Schäfer, A.: A Critical Review of New Mobility Services for Urban Transport. Transp. Res. Procedia. 14, 3294-3303 (2016).

[16.] Stein, M., Meurer, J., Boden, A., Wulf, V.: Mobility in later life - Appropriation of an integrated transportation platform. In: Conference on Human Factors in Computing Systems 2017. S. 5716-5729. , CHI (2017).

[17.] Wu, Y.J., Liu, W.-J., Yuan, C.-H.: A mobile-based barrier-free service transportation platform for people with disabilities. Comput. Human Behav. (2018).

[18.] Tian, C., Huang, Y., Liu, Z., Bastani, F., Jin, R.: „Noah: a dynamic ridesharing system“. In: Proceedings of the 2013 ACM SIGMOD International Conference on Management of Data, 985-988 (2013).

[19.] Ma, S., Zheng, Y., Wolfson, O.: T-share: A large-scale dynamic taxi ridesharing service. In: 2013 IEEE 29th International Conference on Data Engineering (ICDE), 410-421 (2013).

[20.] Cao, B., Alarabi, L., Mokbel, M.F., Basalamah, A.: Sharek: A scalable dynamic ride sharing system. 2015 16th IEEE Int. Conf. Mob. Data Manag. 1, 4-13 (2015).

[21.] Qadir, H., Khalid, O., Khan, M.U., Khan, A.U.R., Nawaz, R.: An optimal ride sharing recommendation framework for carpooling services. IEEE Access. 6 , 66296-62313 (2018)

[22.] Hensher, D.: Future bus transport contracts under a mobility as a service (MaaS) regime in the digital age: Are they likely to change? Transp. Res. Part A Policy Pract. 98, 86-96 (2017).

[23.] Ratcliffe, J.: Scenario building: a suitable method for strategic property planning? Prop. Manag. 18, 127-144 (2000). https://doi.org/10.1108/02637470010328322.

[24.] Ikonen, V.: Scenario-based design as an approach to enhance user involvement and innovation. In: International Conference on Universal Access in HumanComputer Interaction, 164-173. Springer (2007).

[25.] Rosson, M.B., Caroll, J.M.: Scenario based design. Hum. Comput. Interact. boca raton, FL. 145-162 (2009).

[26.] Wimmer, M.A., Bicking, M.: Collaborative Scenario Building For Policy Modelling. In: Conference: tGov 2011 (2011)
[27.] Scherer, S., Wimmer, M.A., Markisic, S.: Bridging narrative scenario texts and formal policy modeling through conceptual policy modeling. Artif. Intell. law. 21, 455-484 (2013).

[28.] Carroll, J.M.: Scenario-Based Design: Envisioning Work and Technology in System Development. John Wiley \& Sons, Inc., USA (1995).

[29.] Wimmer, M.A., Furdik, K., Bicking, M., Mach, M., Sabol, T., Butka, P.: Open Collaboration in Policy Development: Concept and Architecture to integrate scenario development and formal policy modelling. Empower. open Collab. Gov. 199-219 (2012)

[30.] Fahey, L., Randall, R.M.: Learning from the future: competitive foresight scenarios. John Wiley \& Sons, Inc. (1997).

[31.] Zhang, J., Chang, C.K., Chung, J.Y.: Mockup-driven fast-prototyping methodology for Web requirements engineering. In: COMPAC (Hrsg.) Proceedings 27th Annual International Computer Software and Applications Conference, IEEE, 263-268 (2003).

[32.] Vuillemot, R., Boy, J.: Structuring Visualization Mock-ups at the Graphical Level by Dividing the Display Space. IEEE Trans. Vis. Comput. Graph. 24, 424-434 (2017).

[33.] Huang, Y., Wang, C.-I., Hsu, J.: Leveraging the crowd for creating wireframebased exploration of mobile design pattern gallery. In: Proceedings of the companion publication of the 2013 international conference on Intelligent user interfaces companion, 17-20 (2013).

[34.] Kasacak, L., Rebola, C.B., Braunstein, R., Sanford, J.: Mobile application concept development for remote patient monitoring. In: 2013 IEEE International Conference on Healthcare Informatics, 545-550. IEEE (2013)

[35.] Liu, Z., Thompson, J., Wilson, A., Dontcheva, M., Delorey, J., Grigg, S., Kerr, B., Stasko, J.: Data Illustrator: Augmenting vector design tools with lazy data binding for expressive visualization authoring. In: Proceedings of the $2018 \mathrm{CHI}$ Conference on Human Factors in Computing Systems, 1-13 (2018). 